\title{
Willingness of patients with chronic disease in rural China to contract with family doctors: implication for targeting characteristics
}

Jie Li ${ }^{1}$, Jie Li ${ }^{1,2}$, Peipei $\mathrm{Fu}^{1,2}$, Yan Chen ${ }^{3}$, Xue Tang ${ }^{4}$, Zhixian $\mathrm{Li}^{1}$, Shijun Yang ${ }^{1}$, Chen Yan ${ }^{1}$, Wenjuan Li', Zhen Gui ${ }^{1}$ and Chengchao Zhou ${ }^{1,2^{*}}$

\begin{abstract}
Background: Rural residents with chronic conditions have a stronger need for health services, which should make using family doctor contract services a priority. This study aimed to evaluate the rate of willingness among rural residents with chronic conditions to contract with family doctors and examine its determinants.

Methods: A cross-sectional study was conducted from May, 2018 to June, 2018 in Shandong Province in China. A total of 769 rural unsigned residents with chronic conditions were included in the analysis. Using the Andersen model as the theoretical framework, logistic regression models were chosen to analyse the factors associated with willingness to contract with family doctors.

Results: This study found that the rate of willingness to contract with family doctors among chronic patients in rural Shandong was $46.7 \%$. A higher willingness was observed in those living a further distance from the village clinic (more than $600 \mathrm{~m}$ : $\mathrm{OR}=1.85,95 \% \mathrm{Cl}=1.17-2.93$ ), having received publicity for family doctor contract services $(\mathrm{OR}=1.71,95 \% \mathrm{Cl}=1.06-2.76)$, reporting need for utilizing a chronic disease management program $(\mathrm{OR}=3.36,95 \%$ $\mathrm{Cl}=2.20-5.23)$, and reporting need for higher medical insurance reimbursement $(\mathrm{OR}=1.91,95 \% \mathrm{Cl}=1.28-2.83)$.

Conclusions: The prevalence of contract willingness was relatively low among unsigned rural residents with chronic conditions in rural Shandong, China. The need factors were powerful factors affecting their willingness to contract with family doctors. The government should therefore strengthen targeted publicity and education to rural residents with chronic conditions and provide targeted healthcare services, such as chronic disease management programs and medical services with higher reimbursement rates, to promote their willingness to contract with family doctors.
\end{abstract}

Keywords: Contract willingness, Chronic conditions, Family doctor, Family doctor contract services, Andersen model

\section{Introduction}

The increasing morbidity of chronic noncommunicable diseases resulting from the rapid ageing population is a great challenge for the healthcare system. In China, the prevalence of hypertension and diabetes in adults is

\footnotetext{
*Correspondence: zhouchengchao@sdu.edu.cn

${ }^{1}$ Centre for Health Management and Policy Research, School of Public Health, Cheeloo College of Medicine, Shandong University, Jinan 250012, China

Full list of author information is available at the end of the article
}

27.5 and $11.9 \%$, respectively, in 2020 [1]. Strengthening the primary health care (PHC) system is an important measure to address this challenge. The PHC system has contributed substantially to a reduction in the burden of diseases [2]. China has introduced several policies to build integrated delivery systems based on the PHC to prevent and manage chronic diseases [3]. Family doctor contract services (FDCS) were one of the policies, they were adopted as a fundamental healthcare policy in 2009 [4] and extended to a large scale in 2016.

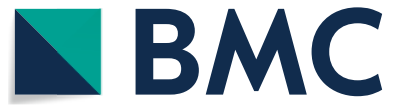

(c) The Author(s) 2021. Open Access This article is licensed under a Creative Commons Attribution 4.0 International License, which permits use, sharing, adaptation, distribution and reproduction in any medium or format, as long as you give appropriate credit to the original author(s) and the source, provide a link to the Creative Commons licence, and indicate if changes were made. The images or other third party material in this article are included in the article's Creative Commons licence, unless indicated otherwise in a credit line to the material. If material is not included in the article's Creative Commons licence and your intended use is not permitted by statutory regulation or exceeds the permitted use, you will need to obtain permission directly from the copyright holder. To view a copy of this licence, visit http://creativecommons.org/licenses/by/4.0/. The Creative Commons Public Domain Dedication waiver (http://creativeco mmons.org/publicdomain/zero/1.0/) applies to the data made available in this article, unless otherwise stated in a credit line to the data. 
FDCS was launched in Shandong Province in 2016 [5], targeting the entire population and focusing on priority populations, such as the elderly, pregnant women, and patients with hypertension, diabetes, and other chronic diseases. FDCS aims to provide residents with proactive, continuous, and comprehensive primary health care by establishing stable partnerships between community residents and family doctors [4]. In addition, residents who contract with family doctors can obtain more benefits, such as access to chronic disease management programs, the green channels in referrals to specialists, and higher medical insurance reimbursement rates by visiting family doctors. Residents can choose their family doctor voluntarily and free to sign contracts. The contracts generally last for 1 year, and the residents can change the contracted doctors after the contract period expires.

The positive effects of FDCS have been reported in previous studies [6, 7]. FDCS can improve people's access to primary health care and improve the health of community residents [8]. It also helps residents with chronic diseases to improve their health-related awareness, selfmanagement behaviours, and treatment compliance. One study from China indicated [9] that approximately $80.79 \%$ of contracted patients had implemented noncommunicable diseases self-management, while only $55.57 \%$ of noncontracted patients did so. Another study [10] found that the blood pressure and blood control rates for the contracted group were higher than those of their counterparts, reaching up to 85.6 and $72.7 \%$ respectively. Therefore, residents with chronic conditions should make using family doctor contract services a priority.

Improving patients' willingness to contract with family doctors is significant for their health. However, previous study showed that distrust in the quality of primary care and misunderstandings about family doctors are key barriers to signing contracts [11]. In addition, some studies have indicated a lower willingness to contract with family doctors among the general population [12-14], and the reasons mainly include poor access to regular medical care and poor publicity of FDCS. Unfortunately, existing studies about residents' willingness to contract with family doctors mainly focus on the general population, and little is known about this topic among patients with chronic diseases.

To remedy this gap, this study aimed to evaluate the rate of willingness to contract with family doctors among rural patients with chronic conditions, and explore the factors associated with their willingness, to provide essential information to promote FDCS among patients with chronic diseases in rural Shandong, China.

\section{Conceptual framework}

The Anderson model $[15,16]$ is a patient-based behavioural model that is widely used in studies on health service utilization. It postulates that health care utilization is determined by predisposing factors (age, sex, race, social class), enabling factors (socioeconomic factors, insurance), and need factors (illness-related factors). Currently, it is also used in the study of older people's intended use of services [17-22]. Based on a previous study [23], we used the Anderson model to guide our current study (Appendix Fig. 1).

A range of predictors that may explain residents' willingness to contract with family doctors have been identified in previous studies, such as 1) predisposing characteristics, including age, gender, educational level, and employment status [24-26]; 2) enabling resources, including marital status, financial condition, health insurance, distance to the village clinic, awareness of FDCS, and publicity of FDCS [12, 24]; and 3) need factors, including self-rated health status and the number of chronic diseases [26, 27]. Although the Andersen model includes "need factors", limited attention has been given to need factors [28]. A previous study indicated that residents contracted with their family doctors based mainly on their real health care needs [29, 30]. Therefore, it is necessary to consider more need factors. In our study, we add three need factors related to chronic patients' willingness into the Andersen model: need for utilizing referrals to specialists, need for utilizing chronic disease management programs and need for higher medical insurance reimbursement rates.

\section{Methods}

\section{Study populations and sampling}

A cross-sectional survey was conducted in three cities in Shandong Province from May to June 2018. Located in the northeast, central, and west of Shandong Province, Binzhou, Zibo, and Liaocheng were included in this study, which represent the medium, high, and low levels of economic status according to the GDP per capita (2018), respectively. A multistage stratified cluster sampling method was used to select participants, and all sampling processes followed strict randomization principles. First, we selected two counties from each city. Then, within each county, five townships were selected and six villages in each township were chosen. Finally a total of 2979 rural residents were recruited for the survey. According to our research purposes, only participants who: 1) had chronic diseases, 2) contracted with family doctors, and 3) had questionnaires that were without logical errors, were included. A total 
of 769 eligible questionnaires were included in the final analysis (Appendix Fig. 2).

All the participants were interviewed face-to-face using a structured questionnaire by trained interviewers. To obtain complete and accurate data, we excluded participants who could not answer independently and with hospital-diagnosed psychiatric disorders. Only one member of a family (generally the main income earner or the elderly) was recruited in this study.

\section{Measures}

Contract willingness was measured by a question for unsigned rural residents with chronic diseases: "Family doctor contract services is a program that can provide people with primary and continuing health care services after contracting with family doctors. It is voluntary. Would you contract with a family doctor?" (yes, no).

Predisposing characteristics were age (64 or below, 65 or above), gender (female, male), educational level (illiteracy; primary school; junior middle school; senior high school or above), and employment status (unemployed, employed). As people with chronic diseases are mostly middle-aged and elderly people, age was divided into two groups by 65 years old.

Enabling resources were marital status (married, unmarried), health insurance (none, have), household annual income, distance to the village clinic, awareness of FDCS (never heard about it, know little about it, know much about it), and publicity of FDCS (yes, no). Awareness of FDCS was measured with the question "Do you know about the family doctor contract services?". The publicity of FDCS was measured with the question "As far as you know, have you ever received publicity about family doctor services?"

Need factors included self-reported health status (good, general, bad), the number of chronic diseases $(1, \geq$ 2 ), need for utilizing referrals to specialists (yes, no), need for utilizing chronic disease management program (yes, no), and need for higher medical insurance (MI) reimbursement rates (yes, no). For the number of chronic diseases, using a yes-or-no format, participants were asked to report nine chronic diseases (e.g, hypertension, diabetes mellitus, cardiovascular and cerebrovascular diseases, respiratory disease). A summated score was used for the analysis, with a high score indicating more chronic conditions. The need for utilizing referrals to specialists was measured with the question "If a family doctor contract service can help your referrals to specialists, would you like to use it?". Need for utilizing chronic disease management program was measured with the question "If family doctor contract service can help your chronic disease management, would you like to use it?". The need for higher medical insurance (MI) reimbursement rates were measured with the question "If a family doctor contract service can increase the proportion of medical insurance reimbursement for medical services, would you like to use it?"

\section{Ethical considerations}

This study was approved by the Ethical Committee of Shandong University School of Public Health. Our survey was voluntary, and residents could refuse to participate. All participants (the guardian of illiterate participants) provided informed consent before the face-to-face interview. The data used in this study were anonymized before use. All procedures performed in this study involving human participants were in accordance with the Declaration of Helsinki (as revised in 2013).

\section{Data analysis}

Descriptive statistics (frequencies and percentages) were employed to describe the sociodemographic features of the participants. Afterward, chi-square $\left(x^{2}\right)$ tests were used to test the relationships between potential factors and willingness to contract with family doctors in rural residents. Multivariable logistic regression was conducted to explore determinants of willingness to contract with family doctors. We incorporated the factors with $P<0.2$ in the results of $X^{2}$ into the logistical model. All statistical analyses were conducted using STATA version 16.0 (Statacorp, College Station, TX). Statistical significance was set at $p<0.05$.

\section{Results}

\section{Characteristics of participants}

A total of 769 unsigned rural patients with chronic diseases were included in the analysis. Table 1 shows the characteristics of the samples and the differences among rural residents' willingness to contract with family doctors. Among the 769 participants, 46.7\% $(N=359)$ were willing to contract with family doctors, and 53.3\% $(N=410)$ were unwilling to contract with family doctors. Of the 769 participants, $45.5 \%$ were elderly ( $\geq 65$ years), $58.0 \%$ were female, $35.8 \%$ were illiterate, $70.4 \%$ were employed, $83.2 \%$ were married, $98.3 \%$ had medical insurance, $39.6 \%$ reported fair self-rated health status, and $72.1 \%$ had at least one chronic disease. Approximately $77.5 \%$ of participants responded that they did not know about FDCS. Participants who stated that no one has ever publicized family doctor contract services accounted for approximately $84.5 \%$. A total of $77.5 \%$ of the participants reported their need for utilizing chronic disease management programs, and $58.0 \%$ of them reported their need for utilizing referrals to specialists. Chi-square tests showed that there were statistically significant differences in gender, awareness of FDCS, publicity of FDCS, 
Table 1 Characteristics of unsigned rural patients with chronic diseases in Shandong, China, 2018 ( N=769)

\begin{tabular}{|c|c|c|c|c|}
\hline \multirow[t]{2}{*}{ Characteristics } & \multirow[t]{2}{*}{ Frequency (\%) } & \multicolumn{2}{|c|}{ Willingness to contract with FDs ${ }^{\mathrm{a}}$} & \multirow[t]{2}{*}{$P$} \\
\hline & & No & Yes & \\
\hline Observations & $769(100.00)$ & $410(53.32)$ & 359(46.68) & \\
\hline Gender & & & & 0.008 \\
\hline Male & $323(42.00)$ & 154(47.68) & $169(52.32)$ & \\
\hline Female & $446(58.00)$ & $256(57.40)$ & 190(42.60) & \\
\hline Age (years) & & & & 0.131 \\
\hline$<65$ & $419(54.49)$ & 213(50.84) & 206(49.16) & \\
\hline$>=65$ & $350(45.51)$ & 197(56.29) & 153(43.71) & \\
\hline Education level & & & & 0.121 \\
\hline Illiterate & $275(35.76)$ & 157(57.09) & 118(43.00) & \\
\hline Primary school & 254(33.03) & 140(55.12) & 114(44.88) & \\
\hline Junior middle school & 182(23.67) & $87(47.80)$ & $95(52.20)$ & \\
\hline Senior high school or above & $58(7.54)$ & $26(44.83)$ & $32(54.69)$ & \\
\hline Employment status & & & & 0.452 \\
\hline Unemployed & $220(28.61)$ & $122(55.45)$ & $98(44.55)$ & \\
\hline Employed & $549(71.39)$ & $288(52.46)$ & $261(47.54)$ & \\
\hline Marital status & & & & 0.667 \\
\hline Married & $640(83.22)$ & $339(52.97)$ & $301(47.03)$ & \\
\hline Single/divorce/widow & 129(16.78) & $71(55.04)$ & $63(44.96)$ & \\
\hline Health insurance & & & & 0.549 \\
\hline None & 13(1.69) & $8(64.29)$ & $5(35.71)$ & \\
\hline Have & $756(98.31)$ & $402(53.55)$ & $354(46.45)$ & \\
\hline Household income $^{b}$ & & & & 0.857 \\
\hline Q1 & 195(25.42) & 100(51.28) & $95(48.72)$ & \\
\hline Q2 & $189(24.64)$ & 103(54.50) & $86(45.50)$ & \\
\hline Q3 & 194(25.29) & $101(52.06)$ & $93(47.94)$ & \\
\hline Q4 & $189(24.64)$ & 104(55.03) & $85(44.97)$ & \\
\hline Distance to the village clinic & & & & 0.147 \\
\hline 0-199m & $214(27.83)$ & $128(59.81)$ & $86(40.19)$ & \\
\hline 200-399m & $219(28.48)$ & 108(49.32) & $111(50.68)$ & \\
\hline $400-599 m$ & 159(20.68) & $82(51.57)$ & $77(48.43)$ & \\
\hline More than $600 \mathrm{~m}$ & $177(23.02)$ & $92(51.98)$ & $85(48.02)$ & \\
\hline Awareness of FDCS & & & & 0.006 \\
\hline Never heard of it & $596(77.50)$ & $336(53.84)$ & $260(46.16)$ & \\
\hline Know little about it & 147(19.12) & $64(43.54)$ & $83(56.46)$ & \\
\hline Know it well & $26(3.38)$ & 10(38.46) & $16(61.54)$ & \\
\hline Publicity of FDCS & & & & $<0.001$ \\
\hline No & $650(84.53)$ & $365(56.15)$ & $285(43.85)$ & \\
\hline Yes & 119(15.47) & $45(37.82)$ & $74(62.18)$ & \\
\hline Self-rated health status & & & & 0.432 \\
\hline Good & 209(27.18) & $106(50.72)$ & 103(49.28) & \\
\hline Fair & 305(39.66) & $160(52.46)$ & $145(47.54)$ & \\
\hline Bad & 255(33.16) & $144(56.47)$ & $111(43.53)$ & \\
\hline The number of chronic diseases & & & & 0.593 \\
\hline 1 & $530(72.14)$ & 286(53.96) & $244(46.04)$ & \\
\hline$>=2$ & $239(27.86)$ & 124(51.88) & 115(48.12) & \\
\hline Referrals to specialists & & & & $<0.001$ \\
\hline No & $458(59.56)$ & $303(66.16)$ & 155(33.84) & \\
\hline Yes & $311(40.44)$ & $107(34.41)$ & 204(65.59) & \\
\hline
\end{tabular}


Table 1 (continued)

\begin{tabular}{|c|c|c|c|c|}
\hline \multirow[t]{2}{*}{ Characteristics } & \multirow[t]{2}{*}{ Frequency (\%) } & \multicolumn{2}{|c|}{ Willingness to contract with FDs ${ }^{\mathrm{a}}$} & \multirow[t]{2}{*}{$P$} \\
\hline & & No & Yes & \\
\hline Chronic disease management programs & & & & $<0.001$ \\
\hline No & $446(58.00)$ & $314(70.40)$ & $132(29.60)$ & \\
\hline Yes & $323(42.00)$ & $96(29.72)$ & $227(70.28)$ & \\
\hline Higher MI reimbursement rates ${ }^{d}$ & & & & $<0.001$ \\
\hline No & $491(57.23)$ & $341(69.45)$ & 150(30.55) & \\
\hline Yes & $367(42.77)$ & $120(32.70)$ & $247(63.70)$ & \\
\hline
\end{tabular}

Note: ${ }^{\text {a }}$ FDs indicates family doctors; ${ }^{\mathrm{b}}$ Quartile 1 (Q1) is the poorest and Quartile 4 (Q4) is the richest; ${ }^{\mathrm{c}}$ FDCS indicates family doctor contract service; ${ }^{\mathrm{d}}$ MI indicates medical insurance

need for utilizing referrals to specialists, need for utilizing chronic disease management programs, and need for higher MI reimbursement rates.

\section{Factors associated with participants' willingness to contract with family doctors}

Table 2 shows the determinants of willingness to contract with family doctors. For the enabling factors, residents who lived a greater distance from the village clinic (more than $600 \mathrm{~m}$ : $\mathrm{OR}=1.85,95 \% \mathrm{CI}=1.17-2.93$ ) and received FDCS publicity $(\mathrm{OR}=1.71,95 \% \mathrm{CI}=1.06-2.76)$ had a significantly higher willingness to contract with family doctors. With the need factors, residents reporting the need for utilizing chronic disease management programs $(\mathrm{OR}=3.36,95 \% \mathrm{CI}=2.20-5.23)$ and the need for higher $\mathrm{MI}$ reimbursement $(\mathrm{OR}=1.91,95 \% \mathrm{CI}=1.28-2.83)$ were more likely to contract with family doctors.

\section{Discussion}

In recent years, the Chinese government has devoted more resources to promoting FDCS, and factors that may influence contract willingness are therefore significant to their implementation. Based on the Andersen model, this study explores the factors associated with of willingness to contract with family doctors for patients with chronic diseases living in rural areas. The role of need factors in affecting patients' willingness to contract with family doctors was emphasized. The findings of this study will contribute to encouraging unsigned patients to contract with family doctors, to achieve the goal of FDCS system coverage.

In this study, only approximately $46.7 \%$ of unsigned rural patients with chronic diseases were willing to contract with family doctors. Residents are more willing to accept family doctors in developed countries, such as the United States (94\%) [31] and Germany (74\%) [32]. Thus, measures should be taken to promote their willingness to contract. In China, this rate was similar to another survey in Luzhou in 2019, where $46.62 \%$ of unsigned residents wanted to contract with family doctors [33]. It was lower than that in Xuzhou in 2018 (57.84\%) [12] and in Henan Province in 2017 (74.5\%) [25]. A possible explanation for this difference was that we only focused on residents in rural areas, and most of the previous studies were in urban areas. In general, rural residents had significantly lower willingness to sign contracts than those in urban areas [25]. In China, a shortage of well-trained and qualified village doctors, particularly in rural areas, is one of the main barriers to family doctor visits for residents [34]. Data from the China Health Statistics revealed that there were only, on average, 1.3 licenced physicians per thousand people in rural areas in 2018 [35]. The precondition for residents' willingness to enroll is their trust in the quality of primary care and competency of family doctors. Hence, measures should be taken to increase the competence of primary health-care institutions, especially in rural China.

For enabling resources, it was interesting that residents who lived a further distance from the village clinic were more likely to contract with family doctors, which is contrary to previous studies [36]. In general, the spatial accessibility of healthcare is lower in rural areas, which increases rural residents' time spent travelling and decreases their opportunities to visit family doctors. It seems that they are unwilling to contract with family doctors. However, family doctors can provide home visits for free, and residents whose homes are far away from the village clinic can obtain free door-to-door visits when needed. Accordingly, it is not difficult to understand why they were more likely to contract.

This study indicated that residents who received FDCS publicity were more likely to sign contracts, which is consistent with previous studies [24]. More publicity of FDCS provides residents more details about family doctors, and their potential benefits. Although the Chinese government has made efforts to promote the policy of family doctor service, residents in rural areas still have limited knowledge of the policy [37]. Rural residents generally 
Table 2 Multivariable logistic model of willingness to contract with family doctors among patients with chronic diseases in Shandong, China, 2018

\begin{tabular}{|c|c|c|c|}
\hline Characteristics & $\begin{array}{l}\text { Model } \\
\text { Odds Ratio }\end{array}$ & $95 \% \mathrm{Cl}$ & $P$-value \\
\hline \multicolumn{4}{|l|}{ Gender } \\
\hline Male & 1 & & \\
\hline Female & 0.73 & $0.50-1.05$ & 0.088 \\
\hline \multicolumn{4}{|l|}{ Age (years) } \\
\hline$<65$ & 1 & & \\
\hline$>=65$ & 0.96 & $0.68-1.35$ & 0.805 \\
\hline \multicolumn{4}{|l|}{ Education level } \\
\hline Illiterate & 1 & & \\
\hline Primary school & 1.01 & $0.67-1.52$ & 0.969 \\
\hline Junior middle school & 1.29 & $0.80-2.09$ & 0.299 \\
\hline Senior high school or above & 1.04 & $0.51-2.11$ & 0.909 \\
\hline \multicolumn{4}{|l|}{ Distance to the village clinic } \\
\hline 0-199m & 1 & & \\
\hline 200-399m & 1.41 & $0.92-2.17$ & 0.117 \\
\hline $400-599 m$ & 1.57 & $0.98-2.52$ & 0.058 \\
\hline More than $600 \mathrm{~m}$ & 1.85 & $1.17-2.93$ & 0.008 \\
\hline \multicolumn{4}{|l|}{ Awareness of FDCS ${ }^{b}$} \\
\hline Never heard of it & 1 & & \\
\hline Know little about it & 1.36 & $0.88-2.11$ & 0.163 \\
\hline Know it well & 1.10 & $0.43-2.87$ & 0.838 \\
\hline \multicolumn{4}{|l|}{ Publicity of FDCS } \\
\hline No & 1 & & \\
\hline Yes & 1.71 & $1.06-2.76$ & 0.028 \\
\hline \multicolumn{4}{|l|}{ Referrals to specialists } \\
\hline No & 1 & & \\
\hline Yes & 1.38 & $0.92-2.07$ & 0.119 \\
\hline \multicolumn{4}{|c|}{ Chronic disease management programs } \\
\hline No & 1 & & \\
\hline Yes & 3.36 & $2.20-5.23$ & $<0.001$ \\
\hline \multicolumn{4}{|c|}{ Higher MI reimbursement rates ${ }^{c}$} \\
\hline No & 1 & & \\
\hline Yes & 1.91 & $1.28-2.83$ & 0.001 \\
\hline
\end{tabular}

Note: ${ }^{a}$ FDCS indicates family doctor contract service; ${ }^{\mathrm{b}} \mathrm{Ml}$ indicates medical insurance

${ }^{*} P<0.05,{ }^{*} P<0.01,{ }^{* * *} P<0.001$

have a low level of education and know little about the concept of a "family doctor". Therefore, targeted publicity should be strengthened for chronically ill populations to improve their willingness to sign contracts.

The significant role of need factors on residents' willingness to contract with family doctors was found in this study. We found that residents who reported their need for utilizing chronic disease management programs or the need for higher MI reimbursement rates were more willing to contract with family doctors.
Residents with chronic diseases have a high need for healthcare services, if patients who contract with family doctors can receive more healthcare services, such as chronic disease management programs and medical services with higher reimbursement rates, they will be willing to sign contracts. Therefore, targeted services should be provided to improve their willingness to sign contracts.

There are several limitations in this study. First, the data we used were cross-sectional, making it impossible to draw causal inferences but only associations, and further studies are needed to explore the causal relationships. Second, the information used in this study was measured by self-reported information, which might result in recall bias. Finally, other factors, such as relationship with doctors, and satisfaction of participants, were not considered, which might also be significant determinants of willingness to enroll. Despite these limitations, we only focused on patients with chronic diseases living in rural areas, which is significant for making targeted recommendations for improving the implementation of FDCS in rural China.

\section{Conclusion}

The prevalence of willingness to contract with family doctors was relatively low among unsigned rural patients with chronic conditions in rural Shandong, China. Factors including the distance to village clinics, publicity of FDCS, need for utilizing chronic disease management programs, and need for higher medical insurance reimbursement rates were associated with contract willingness. This study demonstrated that need factors were powerful factors explaining residents' willingness to contract with family doctors. Therefore, to promote their willingness to contract, the government should strengthen targeted publicity to rural residents with chronic conditions. In addition, targeted services should be provided to improve their willingness to sign contracts.

\section{Abbreviations}

FDCS: Family doctor contract services; CDMP: Chronic disease management program; MI: Medical insurance.

\section{Supplementary Information}

The online version contains supplementary material available at https://doi. org/10.1186/s12875-021-01553-2.

Additional file 1: Appendix Figure 1 Andersen Model of factors influencing willingness to contract with family doctors in rural residents with chronic diseases.

Additional file 2: Appendix Figure 2 Flow chart of sample selection. 


\section{Acknowledgements}

We thank the officials of health agencies, all participants and staffs at the study sites for their cooperation.

\section{Authors' contributions}

Conceptualization, Writing - review and editing, Funding Acquisition, Supervision: Chengchao Zhou; Methodology: Jie Li, Yan Chen, Xue Tang; Formal analysis and investigation: Peipei Fu, Zhixian Li, Shijun Yang, Chen Yan, Wenjuan Li, Zhen Gui; Investigation, Writing - original draft preparation: Jie Li. The authors read and approved the final manuscript.

\section{Funding}

This study was supported by the National Natural Science Foundation of China (Grant Numbers 71974117, 71774104, 71473152,), the China Medical Board (16-257), and Cheeloo Youth Scholar Grant, Shandong University (IFYT1810, IFYT181031). The funding bodies had no role in the design, data collection, analysis, interpretation of the data, or writing of this article.

\section{Availability of data and materials}

The datasets used and/or analysed during the current study are available from the corresponding author (Prof. Chengchao Zhou) upon reasonable request.

\section{Declarations}

\section{Ethics approval and consent to participate}

This study was approved by the Ethical Committee of Shandong University School of Public Health. Our survey was voluntary, and residents could refuse to participate. All participants (the guardian of illiterate participants) provided informed consent before the face-to-face interview. The data used in this study were anonymized before use. All procedures performed in this study involving human participants were in accordance with the Declaration of Helsinki (as revised in 2013).

\section{Consent for publication}

Not applicable.

\section{Competing interests}

The authors declare that they have no competing interests.

\section{Author details}

${ }^{1}$ Centre for Health Management and Policy Research, School of Public Health, Cheeloo College of Medicine, Shandong University, Jinan 250012, China. ${ }^{2} \mathrm{NHC}$ Key Lab of Health Economics and Policy Research, Shandong University, Jinan 250012, China. ${ }^{3}$ School of Public Health, Wannan Medical College, Wuhu 241002, China. ${ }^{4}$ Department of Health Economics, School of Public Health, Fudan University, Shanghai 200032, China.

Received: 26 January 2021 Accepted: 30 September 2021

Published online: 14 October 2021

\section{References}

1. National Health Commission of the People's Republic of China. Press conference of Report on nutrition and chronic diseases of Chinese residents. Accessed 17 July 2021; http://www.nhc.gov.cn/xcs/s3574/202012/bc437 9ddf4324e7f86f05d31cc1c4982.shtml.

2. Li X, Lu J, Hu S, Cheng KK, De Maeseneer J, Meng Q, et al. The primary health-care system in China. Lancet. 2017;390(10112):2584-94.

3. Li X, Krumholz HM, Yip W, Cheng KK, De Maeseneer J, Meng Q, et al. Quality of primary health care in China: challenges and recommendations. Lancet. 2020;395(10239):1802-12.

4. The State Council. Guidance of the State Council on the Establishment of a General Practitioner System. http://www.gov.cn/zhengce/content/ 2011-07/06/content_6123.htm. Accessed 20 Dec 2020.

5. Shandong Provincial Health Commission. The Implementation Advice on Accelerating and Improving the Signing Service of Family Doctors. http:// www.cqvip.com/QK/82539X/201636/671237292.html, Accessed 17 July 2021
6. Li L, Zhong C, Mei J, Liang Y, Li L, Kuang L. Effect of family practice contract services on the quality of primary care in Guangzhou, China: a cross-sectional study using PCAT-AE. BMJ Open. 2018;8(11):e021317.

7. Kuang L, Liang Y, Mei J, Zhao J, Wang Y, Liang H, et al. Family practice and the quality of primary care: a study of Chinese patients in Guangdong Province. Fam Pract. 2015;32(5):557-63.

8. Lai S, Lu L, Zhou Z, Shen C, Yang X, Zhao Y, et al. The effects of family physician-contracted service on health-related quality of life and equity in health in China. Int J Equity Health. 2021;20(1):1-10.

9. Huang J, Zhang T, Wang L, Guo D, Liu S, Lu W, et al. The effect of family doctor-contracted services on noncommunicable disease self-management in Shanghai, China. Int J Health Plann Manag. 2019;34(3):935-46.

10. Huang J, Lu W, Wang L, Zhang T, Liu C, Liu S, et al. A preliminary effect analysis of family doctor and medical insurance payment coordination reform in Changning District of Shanghai, China. BMC Fam Pract. 2019;20(1):60.

11. Yuan S, Wang F, Li X, Jia M, Tian M. Facilitators and barriers to implement the family doctor contracting services in China: findings from a qualitative study. BMJ Open. 2019;9(10):e032444.

12. Li Q, Huang W, Miao C, Jiang J-X, Li H, Zhao H, et al. Study on urban residents' willingness of family doctor contract and its influencing factors in Xuzhou. Chin Health Resour. 2018;21(03):262-6.

13. Jing L, Shu Z, Sun X, Chiu JF, Lou J, Xie C. Factors influencing patients' contract choice with general practitioners in Shanghai: a preliminary study. Asia Pac J Public Health. 2015;27(2 Suppl):77S-85S.

14. Huang J, Liu S, He R, Fang S, Lu W, Wu J, et al. Factors associated with residents' contract behavior with family doctors in community health service centers: a longitudinal survey from China. PLoS One. 2018;13(11):e0208200.

15. Andersen R, Newman JF. Societal and individual determinants of medical care utilization in the United States. Milbank Memor Fund Quart Health Soc. 1973;51(1):95-124.

16. Andersen RM. Revisiting the behavioral model and access to medical care: does it matter? J Health Soc Behav. 1995;36(1):1-10.

17. Natarajan S, Nietert PJ. Hypertension, diabetes, hypercholesterolemia, and their combinations increased health care utilization and decreased health status [J]. J Clin Epidemiol. 2004;57(9):954-61.

18. Fu Y, Guo Y, Bai X, Chui EWT. Factors associated with older people's longterm care needs: a case study adopting the expanded version of the Anderson model in China. BMC Geriatr. 2017;17(1):38.

19. Jang Y, Chiriboga DA, Allen JY, Kwak J, Haley WE. Willingness of older Korean-American adults to use hospice. J Am Geriatr Soc. 2010;58(2):352-6.

20. Werner P, Segel-Karpas D. Factors associated with preferences for institutionalized Care in Elderly Persons: comparing hypothetical conditions of permanent disability and Alzheimer's disease. J Appl Gerontol. 2016;35(4):444-64

21. Zhang $L$, Zeng $Y$, Fang $Y$. The effect of health status and living arrangements on long term care models among older Chinese: a cross-sectional study. PLoS One. 2017;12(9):e0182219.

22. Seidu A-A. Using Anderson's model of health service utilization to assess the use of HIV testing services by sexually active men in Ghana. Front Public Health. 2020:8:512

23. Liu Z, Tan Y, Liang H, Gu Y, Wang $X$, Hao Y, et al. Factors influencing residents' willingness to contract with general practitioners in Guangzhou, China, during the GP policy trial phase: a cross-sectional study based on Andersen's behavioral model of health services use. J Health Care Org Provision Finan. 2019:56:0046958019845484.

24. Li K, Lu C, Wang J, Wang S. Analysis on influence factors of the willingness of community residents to sign up for family doctor Service in Songshan new district of Jinzhou City. Chin J Stroke. 2020;15(02):130-4.

25. Liang S, Yu X, Li C, Zou H, Hu Y, Zhang H. Intention and associated factors of signing a contract with a family doctor team in residents in in Henan Province. Chin Gen Pract. 2017;20(28):3488-92.

26. Zhang $X$, Zhang $X$, Yang $S$, Wang $Y$. Factors influencing residents' decision to sign with family doctors under the new health care reform in China. Int J Health Plann Manag. 2019;34(4):e1800-9.

27. Wang X, Li P, Ma G, Bai S, Ma L. Investigation on the awareness and willingness of family doctor contractual services in urban community-_ take residents of a district of Urumgi as an example. Soft Sci Health. 2019:33(12):52-9. 
28. Gan Y, Li W, Cao S, Dong X, Li L, Mkandawire N, et al. Patients' willingness on community health centers as gatekeepers and associated factors in Shenzhen, China: a cross-sectional study. Medicine (Baltimore). 2016;95(14):e3261.

29. Shang X, Huang Y, Be L, Yang Q, Zhao Y, Wang W, et al. Residents' awareness of family doctor contract services, status of contract with a family doctor, and contract service needs in Zhejiang Province, China: a crosssectional study. Int J Environ Res Public Health. 2019;16(18):3312.

30. Fu P, Wang Y, Liu S, Li J, Gao Q, Zhou C, et al. Analysing the preferences for family doctor contract services in rural China: a study using a discrete choice experiment. BMC Fam Pract. 2020;21(1):1-8.

31. Grumbach K, Selby JV, Damberg C, et al. Resolving the gatekeeper conundrum: what patients value in primary care and referrals to specialists [J]. JAMA. 1999;282(3):261-6.

32. Himmel W, Dieterich A, Kochen MM. Will German patients accept their family physician as a gatekeeper?[J]. J Gen Intern Med. 2000;15(7):496-502.

33. Yu X, Lan L, Xiao W, Li Y, Yao Q, Liu H, et al. Signing willingness and demand survey of unsigned family doctor service residents in Luzhou City, China. China Med Pharm. 2020;10(16):114-8.
34. Wang C, Yan S, Jiang H, Nie Z, Miller M, He Y, et al. Residents' willingness to maintain contracts with family doctors: a cross-sectional study in China. J Gen Intern Med. 2021;36(3):622-31.

35. National Health Commission. The statistics yearbook of national health. Beijing: China Union Medical University Press; 2018

36. Dai J, Zhu X, Li W. Intention and influencing factors of signing a health service contract with the family doctor among among Communitydwelling residents in Yunnan Province. Chin Gen Pract. 2019;22(07):783-8.

37. He J, LiY. Awareness,signing situation and willingness of family doctors contract services in rural areas of Fujian Province. Chin Rural Health Serv Admin. 2019;39(01):51-6.

\section{Publisher's Note}

Springer Nature remains neutral with regard to jurisdictional claims in published maps and institutional affiliations.
Ready to submit your research? Choose BMC and benefit from:

- fast, convenient online submission

- thorough peer review by experienced researchers in your field

- rapid publication on acceptance

- support for research data, including large and complex data types

- gold Open Access which fosters wider collaboration and increased citations

- maximum visibility for your research: over $100 \mathrm{M}$ website views per year

At $\mathrm{BMC}$, research is always in progress.

Learn more biomedcentral.com/submissions 